\title{
EXCESS METHANOL RECOVERY IN BIODIESEL PRODUCTION PROCESS USING A DISTILLATION COLUMN: A SIMULATION STUDY
}

\author{
Bipro Ranjan Dhar ${ }^{1}$, Kawnish Kirtania ${ }^{* 2}$ \\ ${ }^{1}$ Chemical E Biochemical Engineering, University of Western Ontario, London, ON, Canada N6A $5 B 9$ \\ ${ }^{2}$ Chemical Engineering, Bangladesh University of Engineering and Technology, Dhaka, Bangladesh \\ Received 13 October 2009; received in revised form 12 December 2009
}

\begin{abstract}
This paper presents an ASPEN PLUS ${ }^{\mathrm{TM}}$ simulation study for excess methanol recovery in continuous biodiesel production process using a distillation column. The feedstock used for biodiesel production was Triolein containing $15 \%$ free fatty acid (Oleic Acid). The special attention was devoted to the effect of different alcohol to oil ratio and important design and operating parameters of distillation column on excess methanol recovery from the product. The energy consumption is represented by reboiler heat duty of distillation column. Analysis of simulation results shows that for a certain distillation operating condition and reaction parameters it is possible to recover around $95-98 \%$ of excess methanol before phase separation of biodiesel and glycerol, although for high alcohol to oil ratio the energy requirement increases exponentially.
\end{abstract}

Keywords: Biodiesel, Methanol Recovery, Distillation, Simulation, ASPEN PLUS ${ }^{T M}$

DOI:10.3329/cerb.v13i2.3538

\section{Introduction}

Worldwide increasing oil crisis and reducing fossil fuel reserve act as a driving force behind the search of alternative fuels. The major portion of the total energy consumed worldwide is now coming from fossil fuel sources. Fossil fuel sources are non-renewable, and will be exhausted by near future. Biodiesel can be a wonderful replacement to conventional petro-diesel fuel [1], which can be produced from a renewable domestic resource.

Biodiesel is produced through a chemical reaction known as Transesterification. In Transesterification vegetable oil or animal fat (Triglyceride) react in presence of a catalyst with a primary alcohol to give the corresponding alkyl esters of the fatty acid mixture that is found in the parent vegetable oil or animal fat. Triglyceride is a glyceride in which the glycerol is esterfied with long chain acids, known as fatty acids. It is the main constituent of vegetable oil and animal fats [2]. Biodiesel can be produced from different types of feedstock, with a various level of free fatty acids (FFAs) content. The amount of free fatty acid in triglyceride plays a very important role in biodiesel production. FFAs act as a potential contaminant. They react with alkali catalyst to form soap. Soap can cause glycerol separation problem [2]. The production of biodiesel from high FFAs containing feedstock needs a pretreatment to convert the FFAs to ester [3]. This pretreatment process is known as esterification. So, the

*Corresponding author Email:kkdwip@che.buet.ac.bd; $\mathrm{Ph}:+8801716481451$ production of biodiesel process from low-quality feedstock consists of two steps-esterification and transesterification. This two steps approach is also known as acid catalysis followed by alkali catalysis.

Transesterification Reaction (Base Catalyst)

Oil/Fat + Alcohol $\rightarrow$ Biodiesel + Glycerol

Esterification Reaction (Acid Catalyst)

$$
\mathrm{FFA}+\text { Alcohol } \rightarrow \text { Ester }+ \text { Water }
$$

Widely used base catalyst is sodium hydroxide, while the acid catalyst is generally sulfuric acid [3]. Methanol is widely used primary alcohol for producing biodiesel due to the following advantages compared to other alcohols-

- Not expensive.

- Prevent soap formation.

- Reactivity is high [4].

- Methanol recovery comparatively is easier, as it doesn't form azeotrope [5].

The biodiesel production process produces two products: methyl ester (biodiesel) and glycerol. Most biodiesel production process use excess methanol to get high yield. This excess methanol is distributed between the two products [6]. After the biodiesel process is complete, a lot of methanol is available for recovery and reuse. To meet $\mathrm{ASTM}^{1}$ D6751 or EN ${ }^{2} 14214$ stan-

\footnotetext{
${ }^{1}$ ASTM: American Society for Testing and Materials

${ }^{2}$ EN: European Standard
}

(C)Bangladesh Uni. of Engg. $\mathcal{E}$ Tech. 
dards the removal of excess methanol becomes a vital step. Almost every biodiesel standard allows $0.2 \%$ methanol in the final product [7]. Residual methanol in the biodiesel fuel is a major environmental and health safety issue. Methanol is toxic, and the emission of excess methanol from the use of biodiesel can be hazardous for our life and environment. Excess methanol can also make the fuel flammable and more dangerous to handle and store. Besides, Excess methanol may corrode metal components of engine [6,8]. For these reasons, most conventional biodiesel manufacturers waste a lot of unused methanol through washing the final product. Some biodiesel manufacturers are now using distillation column and flash evaporation for methanol recovery [6].

Methanol recovery can make the biodiesel production process more efficient from both economical and environmental point of view, as it can save the input costs for the process as well as helps to maintain the specific standard. And in designing a cost-effective methanol recovery unit energy requirement is the most important parameter, as high energy requirement may increase the cost of biodiesel compared to conventional petro-diesel. Although different research groups have done simulation and lab scale studies on various types of biodiesel production process using various types of feedstock and catalysts, but no attempt has been focused on the energy requirement for methanol recovery unit. Distillation can do the separation very efficiently, but its major disadvantage is the high energy requirement. In USA about 40,000 distillation columns are running in different chemical industries, and they use $3 \%$ of the US total energy consumption [9]. Important variables involved in designing distillation column are operating pressure, temperature, feed composition, feed flow rate, total number of stages, feed location, distillate rate, reflux ratio etc. [10]. To design an efficient and cost-effective methanol recovery system the study of the effects of different design parameters of the process as well as its energy requirement is very important. The key objective of this simulation study was to investigate the energy requirement as well as separation behavior of methanol from the biodiesel and glycerol mixture using a distillation column.

\section{Methanol Recovery Process}

After the completion of transesterification and esterification reactions the excess methanol is distributed to the mixture of the products (biodiesel and glycerol). Usually this mixture is separated by gravity separation, as they have different densities. Methanol recovery unit (MRU) can be used before phase separation. The unreacted methanol act as a phase stabilizer, and reduce the rate of phase separation [6]. Besides, methanol recovery can be carried out immediately following transesterification to reduce the load in downstream units [11]. So, using a distillation column before phase separation (MRU 1) can give some technical advantages to the process.

After phase separation methyl ester (Biodiesel) and glycerol still contain excess methanol (Gerpen et al.; 2004). Two different methanol recovery units can be used to separate methanol from biodiesel and glycerol. This is a common approach of methanol recovery in most conventional biodiesel production processes. Figure 1 shows a process flow diagram of a two steps biodiesel production process with possible methanol recovery units. The energy requirement of distillation column is very high. So, using two different methanol recovery units (MRU $2 \& 3$ ) may increase the installation, operating costs and the cost of production of biodiesel as well. In this study the simulation was done for Methanol Recovery Unit 1 (MRU1).

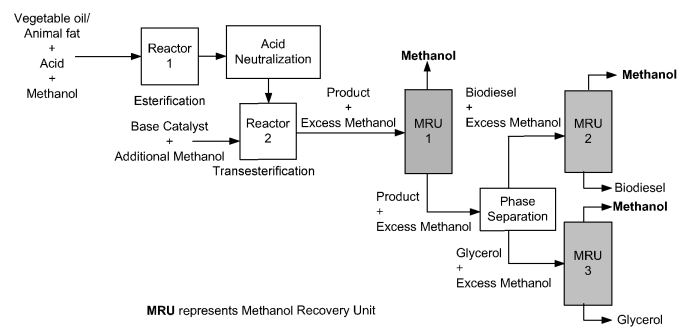

Figure 1: Process Flow Diagram of a Two Steps Biodiesel Production Process with possible Methanol Recovery units

\section{Process Simulation}

Simulation is a widely used tool for design, test and optimization of a chemical process. Now most process designer prefers commercial simulation packages to see and investigate the real effects of different design parameters of the chemical process during operation. Although simulation result does not guarantee $100 \%$ correct result compared to the real process, simulation can provide the opportunity to design and test the unit operation in a short period of time. Besides, simulation can give some results that can't be verified experimentally in laboratory or pilot scale.

To study the effect of methanol to oil ratio and different design parameters of distillation column on energy requirement for methanol recovery before phase separation a process simulation was performed using ASPEN PLUS $^{\mathrm{TM}}$, a very popular and reliable commercial process simulation software package widely used in chemical process industries. ASPEN PLUS ${ }^{\mathrm{TM}}$ has a rich physical properties databank along with strong thermodynamic foundation. Besides, it can be used for 
almost every steps of process design including sensitivity analysis, profitability analysis, and process optimization. The major steps involved in simulation using ASPEN PLUS ${ }^{\mathrm{TM}}$ were:

- Drawing the graphical simulation process flowsheet

- Specifying the components involved in the process

- Selection of a thermodynamic model

- Specifying the operating condition (flow rate, temperature, pressure, composition etc.)

As the aim was to study the methanol recovery unit for the biodiesel production from comparatively high free fatty acid feedstock, a moderate feedstock with $15 \%$ free fatty acid (FFA) was assumed. In process simulation Triolein $\left(\mathrm{C}_{57} \mathrm{H}_{104} \mathrm{O}_{6}\right)$ was used to represent the triglyceride for biodiesel production. And the major free fatty acid found in vegetable oil and animal fat is oleic acid $\left(\mathrm{C}_{18} \mathrm{H}_{34} \mathrm{O}_{2}\right)$, which was chosen to represent the free fatty acid (FFA) in this simulation. So, produced biodiesel is methyl oleate $\left(\mathrm{C}_{19} \mathrm{H}_{36} \mathrm{O}_{2}\right)$.

The developed process flowsheet for simulation is shown in the Figure 2. To simplify the process flowsheet, one Stoichiometric reactor model has been used for both reactions (transesterification and esterification) rather than using two reactors in series. Stoichiometric reactor model is used in ASPEN PLUS ${ }^{\mathrm{TM}}$ simulation when the detail kinetic information of a chemical reaction is not available. Different studies have reported $95-97 \%$ conversion for base catalyzed transesterification [11, 12]. Acid catalyzed esterification as a pretreatment process for converting FFA to ester. This process can convert $98-100 \%$ of FFA to ester $[13,14]$. Due to lack of detailed kinetic information, $97 \%$ and $100 \%$ conversion of reactant were assumed in this simulation for base catalyzed transesterification and acid catalyzed esterification reactions, respectively. ASPEN PLUS ${ }^{\mathrm{TM}}$ provides different types of subroutines or model for distillation options such as DSTWU, Distl, and RadFrac etc. In this case, RadFrac subroutine has been chosen, as it provides much more rigorous calculations compared to other subroutines. Besides, using RadFrac give more freedom to the process designer, as almost all design parameters can be specified by the designer.

The selected operating temperature and pressure of reactor was $65^{\circ} \mathrm{C}$ and, $1 \mathrm{~atm}$ respectively. To increase the inlet feed temperature in distillation column a preheater is used between the reactor and distillation column. The top product (DIS) of distillation column (DIST) represents the recovered excess methanol from product. This excess methanol is recycled for reuse. A stream multiplier (B1) is used to control the amount of methanol in feed to maintain the desired alcohol to oil ratio. The bottom product (BOTTOM) of the distilla- tion column is the mixture of biodiesel, glycerol and residual methanol.

Simulation of mass transfer equipment required the selection of some thermodynamic model. In ASPEN PLUS $^{\mathrm{TM}}$ different thermodynamic models are available such as UNIversal Functional Activity Coefficient (UNIFAC), UNiversal QUAsiChemical (UNIQUAC), Non-Random Two Liquid (NRTL) etc. UNIFAC was chosen, as it can be used can be used when experimental data is not available [15]. However, due to the presence of polar compounds NRTL and UNIQUAC is also preferred in some literatures. The total production capacity of this continuous biodiesel production plant was 7500 tonnes of biodiesel per year. The simulation basis and MRU design specification are shown in Table 1 and Table 2.

Table 1: Simulation basis

\begin{tabular}{ll}
\hline Feedstock & $\begin{array}{l}\text { Triolein (Triglyceride) with 15\% Oleic } \\
\text { Acid (FFA) }\end{array}$ \\
Biodiesel production process & $\begin{array}{l}\text { Acid catalysis followed by alkali catalysis } \\
\text { (Two Steps Process) }\end{array}$ \\
$\begin{array}{l}\text { Methanol to oil ratio } \\
\text { Methanol recovery unit }\end{array}$ & $\begin{array}{l}\text { Distillation Column } \\
\text { Reactor Subroutine }\end{array}$ \\
$\begin{array}{l}\text { Ristillation Subroutine } \\
\text { Reactor Operating Tempera- }\end{array}$ & $\begin{array}{l}\text { RadFrac } \\
65^{\circ} \mathrm{C}\end{array}$ \\
$\begin{array}{l}\text { ture } \\
\text { Reactor Operating Pressure }\end{array}$ & 1 atm \\
$\begin{array}{l}\text { Feed Temperature in Reactor } \\
\text { (Methanol \& Oil) }\end{array}$ & $25^{\circ} \mathrm{C}$ \\
$\begin{array}{l}\text { Feed Pressure in Reactor } \\
\text { Thermodynamic model } \\
\text { Yield }\end{array}$ & 1 atm \\
& UNIFAC \\
& Esterification (100\% conversion of FFA) \\
Total Biodiesel Production ca- & Triglyceride) \\
pacity & 7500 tonnes of biodiesel per year \\
\hline
\end{tabular}

Table 2: MRU design specification

\begin{tabular}{ll}
\hline Feed temperature & $80^{\circ} \mathrm{C}$ \\
Feed Pressure & 0.5 to 1 \\
Total number of stages & 10 \\
Feed Stage & 5 \\
Reflux Ratio & 1 to 4 \\
\hline
\end{tabular}

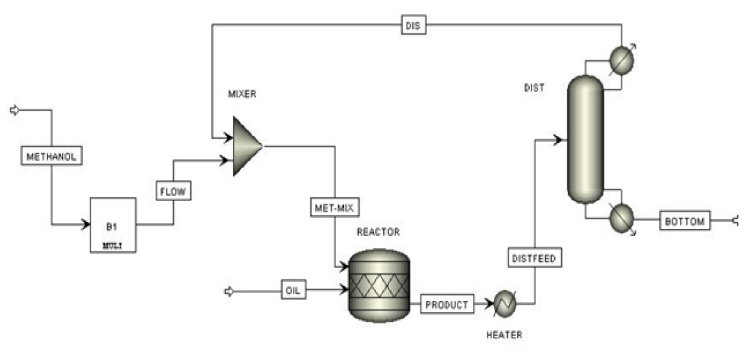

Figure 2: Process Flowsheet Developed in ASPEN PLUS $^{\mathrm{TM}}$ 


\section{Results \& Discussion}

\subsection{Effect of Methanol to Oil Ratio}

To ensure the high yield of biodiesel production, different biodiesel production processes use a wide range of methanol to oil ratio. The optimum methanol and oil ratio for two step biodiesel production process is still unknown. To see the effect of methanol to oil ratio, the sensitivity analysis was done using a wide range of methanol to oil ratio (6:1 to 50:1), keeping the distillation column operating condition fixed. Distillation operating condition were fixed at total number of stages 10 , feed stage 5 , reflux ratio 2 , inlet feed temperature $80^{\circ} \mathrm{C}$ and 0.5 atmospheric pressure. For different methanol to oil ratio it is possible to recover almost $80 \%$ excess methanol at moderate reboiler heat duty. But to get above this range of methanol recovery the required reboiler heat duty increases exponentially, Figure 3. So, it will be intensive to keep the methanol to oil ratio low, to optimize the separation cost using distillation.

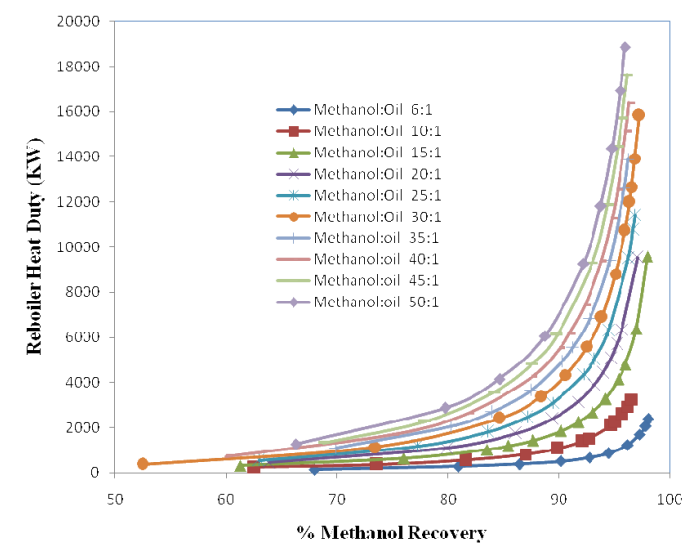

Figure 3: Required Reboiler Heat Duty $(\mathrm{KW})$ for different level of methanol recovery; Total number of stages 10 , feed stage 5 , reflux ratio 2 , column operating pressure $0.5 \mathrm{~atm}$

\subsection{Effect of Reflux Ratio}

For reuse the purity of separated methanol is also very important. In distillation operation higher reflux ratio is usually used to get high purity of product. But, to maintain higher reflux ratio in distillation column required higher reboiler heat duty as well as higher cost for operation. To see the effect of different reflux ratio on energy requirement the sensitivity analysis has been done for two different methanol to oil ratio, and reflux ratio was varied from 1 to 4 . The operating condition of distillation column was total number of stages 10 , feed stage 5, Distillate rate $1500 \mathrm{~kg} / \mathrm{hr}$, inlet feed temperature $80^{\circ} \mathrm{C}$ and 0.5 atmospheric pressure. Figure 4 shows the effect of reflux ratio on reboiler heat duty.
Table 3: Sensitivity Analysis results for the effect of reflux ratio

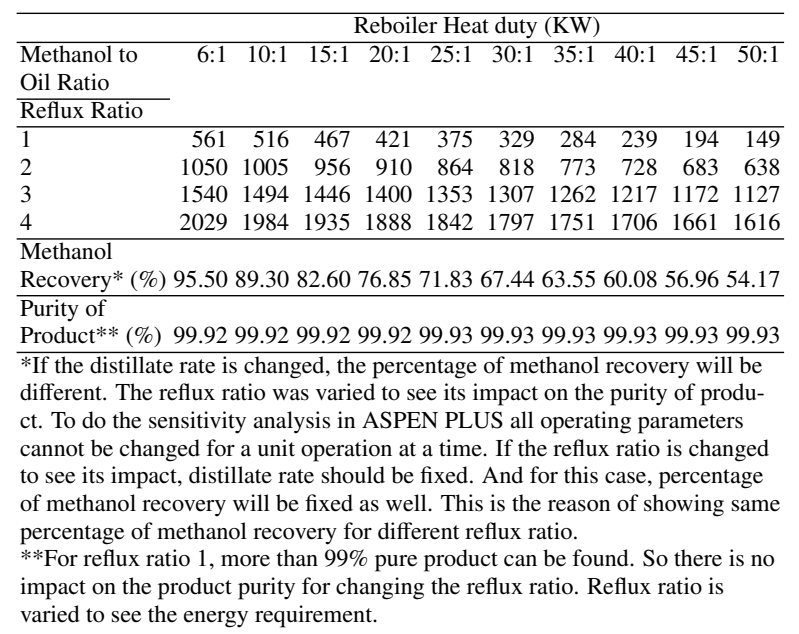

The simulation result shows that for this operating condition above $99 \%$ pure methanol can be obtained (Table 3). So, the separation cost can be minimized by operating distillation column at low reflux ratio. The major reason behind this finding is the low boiling point of methanol compared to biodiesel and glycerol.

\subsection{Effect of Distillation Column Pressure}

To see the influence of pressure variations upon reboiler heat duty sensitivity analysis has been done for two different methanol to oil ratio, and operating pressure was varied from 1 to 0.5 atmospheric pressure. The operating condition of distillation column was total number of stages 10, feed stage 5, Reflux Ratio 1, and inlet feed temperature $80^{\circ} \mathrm{C}$. The simulation result shows that for same level of methanol recovery reboiler heat duty for separation can be reduced under vacuum operation, Figure 5. Usually vacuum distillation is used to separate heat sensitive product that may decompose on heating at atmospheric pressure. During vacuum operation, it is vital to keep the temperatures of the distillate and bottoms streams at low levels. Otherwise, the products may decompose. Besides, vacuum operation needs additional cost.

\section{Conclusion}

Based on the simulation results and performance analysis the following conclusions are drawn:

- Alcohol to oil ratio used in the biodiesel production is the most important process parameter for the development of a methanol recovery unit, as the energy requirement increases with the increase in methanol to oil ratio used. 


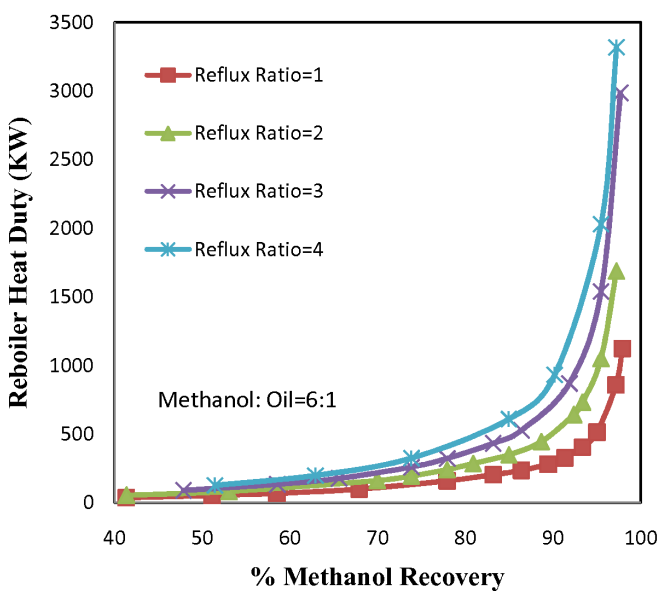

(a)

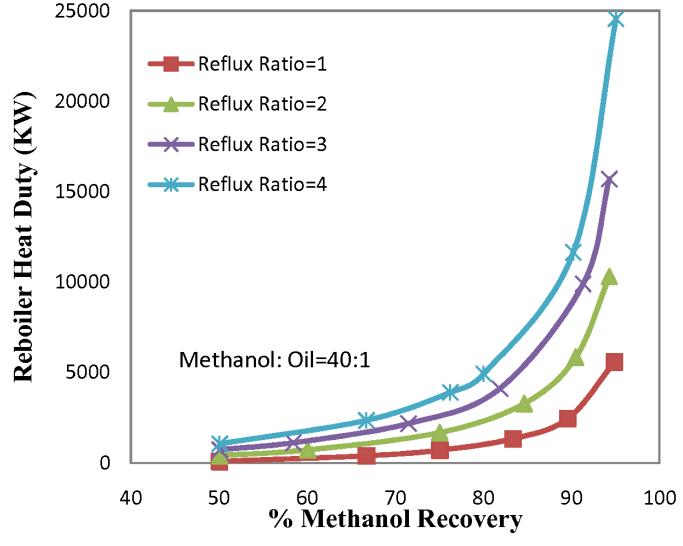

(b)

Figure 4: Effect of Reflux Ratio on Reboiler Heat Duty for various levels of methanol separation; Total number of stages 10 , feed stage 5 , distillate rate $1500 \mathrm{~kg} / \mathrm{hr}$, inlet feed temperature $80^{\circ} \mathrm{C}$, and 0.5 atmospheric pressure

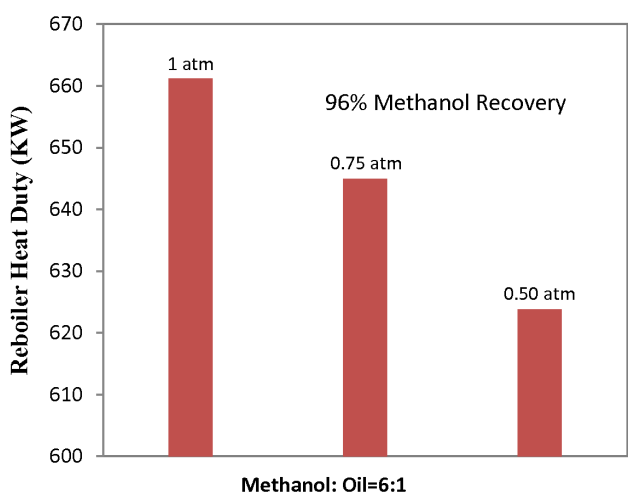

(a)

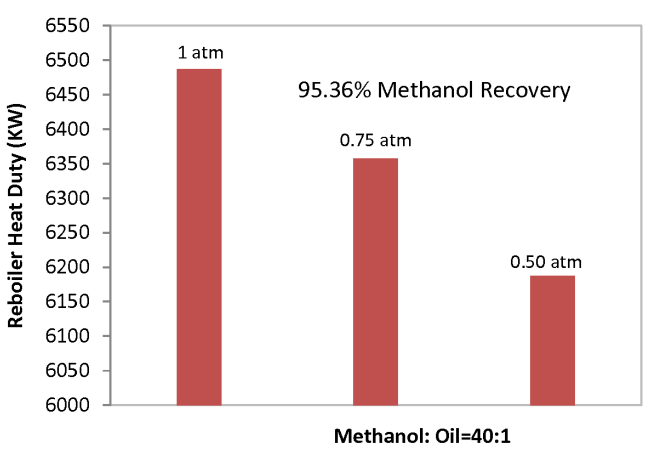

(b)

Figure 5: Effect of Column Pressure (No of stages 10, feed stage 5, reflux ratio 1)

- At certain operating condition of distillation column it is possible to separate almost $95-98 \%$ excess methanol for reuse before phase separation. But after a level of methanol separation operating distillation column becomes verenergy inefficient.

- It is possible to get high purity of methanol for reflux ratio 1 , as the boiling point of methanol is low compared to biodiesel and glycerol.

- The required reboiler heat duty can be reduced under vacuum operation of distillation column.

\section{Acknowledgement}

The financial supports for this simulation study provided by Dr. A. Aroonwilas, and Dr. A. Veawab, Faculty of Engineering, University of Regina, Saskatchewan, Canada is gratefully acknowledged.

\section{References}

[1] C L Peterson DLR, Emissions Tests with an On-Road Vehicle Fueled with Methyl and Ethyl Esters of Rapeseed Oil, in ASAE International Winter Meeting, paper no. 946532, 1994

[2] Canakci M and Gerpen JV, Biodiesel Production from Oils and Fats with High Free Fatty Acids, Transactions of the American Society of Agricultural Engineers, 2001. 44:pp. 1429-1436

[3] S Chongkhong PCCB C Tongurai, Biodiesel production by esterification of palm fatty acid distillate, Biomass and Bioenergy, 2007. 31:pp. 563-568

[4] S Chongkhong PC C Tongurai, Continuous esterification for biodiesel production from palm fatty acid distillate using economical process, in Renewable Energy, 2008

[5] Demirbas A, Biodiesel: A Realistic Fuel Alternative for Diesel Engines, Springer Publication, 2008

[6] V J Gerpen RPDCGK B Shanks, Biodiesel Production Technology, National Renewable Energy Laboratory, Colorado, 2004

[7] J Gerpen JK G Knothe, The Biodiesel Handbook, AOCS Press, 2005

[8] Berrios M and Skelton R, Comparison of purification methods 
for biodiesel, Chemical Engineering Journal, 2008. 144:pp. 459-465

[9] J L Humphrey AS and Koort RA, Separation Technologies: Advances and Priorities,DOE/ID/12920-1, Technical report, U.S. Department of Energy, 1991

[10] Philip CW, Equilibrium Staged Separations, Prentice-Hall, Inc., 1988

[11] Y Zhang DDMMK M A Dube, Biodiesel production from waste cooking oil: 1. Process design and technological assessment, Bioresource Technology, 2003. 89:pp. 1-16

[12] A H West NE D Posarac, Assessment of four biodiesel production processes using HYSYS.Plant, Bioresource Technology, 2008. 99:pp. 6587-6601

[13] Official website of The Northeast Regional Biomass Program (NRBP): http://www.nrbp.org, [last accessed on January 3, 2010]

[14] AS Ramadhas CM S Jayaraj, Biodiesel production from high FFA rubber seed oil, Fuel, 2005. 84:pp. 335-340

[15] Bruce AF, Introduction to Chemical Engineering Computing, John Wiley \& Sons, Inc., 2006 